\title{
O ADVENTO DO MOVIMENTO ESCOTEIRO NO TERRITÓRIO FEDERAL DO AMAPÁ: UMA POLÍTICA DE EDUCAÇÃO EXTRAESCOLAR (1945-1947)
}

Jỗo dE DEUS SANTOS dE SAMPAIO* REGINA LÚCIA DA SILVA NASCIMENTO**

Resumo: O Movimento Escoteiro (ME) trata-se de um modelo político de educação extraescolar introduzido no Brasil a partir de 1910. Diante disso, este estudo faz uma reflexão sobre a história do Escotismo no País, com foco no processo de implantação e consolidação do ME no então Território Federal do Amapá (TFA), situado no extremo Norte da Amazônia brasileira. Seu objetivo é analisar o surgimento de Grupos Escoteiros no TFA, de 1945 a 1947. De natureza qualitativa, tipo documental e bibliográfica, a pesquisa baseou-se nas seguintes fontes: livros, regulamentos/decreto de lei do ME, Relatório de Governo do TFA, Jornal Amapá e fotografias da época. Tais fontes foram analisadas à luz da História Cultural. Inicialmente, foi feito um breve histórico sobre o Escotismo e sua origem no Brasil, destacando o precursor do ME no mundo: BadenPowell. Em seguida, propomos uma abordagem do Escotismo como política de educação não formal/extraescolar no Brasil, enfatizando sua legitimação no país e os ideais do movimento escoteiro. E por fim, apresentaremos a história do Escotismo no TFA (1945-1947). A pesquisa permitiu compreender que apesar de levarem demasiado tempo para se efetivarem no Amapá, os Grupos Escoteiros se constituíram como referências em educação extraescolar durante o Governo de Janary Gentil Nunes. Pois contribuíam com os interesses do governador, ao difundirem por meio de seus ideais, mecanismos de controle, disciplina, higiene, ordem, amor à pátria, indispensáveis à manutenção do Governo no Território.

Palavras-chave: História do Escotismo. Política de Educação extraescolar. Território Federal do Amapá.

\section{The Advent of the Scout Movement in the Federal Territory of Amapá: an extracurricular education policy (1945-1947)}

\begin{abstract}
The Scout Movement (SM) is a political model of extracurricular education introduced in Brazil from 1910. This study reflects on the history of Scouting in Brazil, focusing on the process of implementation and consolidation of the SM in Federal Territory of Amapá (FTA), located in the extreme north of Brazilian Amazon. The purpose of this work is to analyze the advent of Scout Groups in the FTA, from 1945 to 1947. Of qualitative nature, documental and bibliographic type, the research was based on the following sources: books, regulations/SM Law Decree, TFA Government Report, Amapá Newspaper and photographs of the time studied. These sources were analyzed in the light of Cultural History. Initially, a brief history was made on Scouting and its origin in Brazil, highlighting the precursor of the SM in the world: Baden-Powell. Next, we pro-

* Mestrando no Programa de Pós-Graduação em Educação/Universidade Federal do Amapá (PPGED/UNIFAP). E-mail: sampaiojoao@outlook.com

** Doutora em Educação pela Universidade Federal de Uberlândia (UFU). Professora do PPGED - Mestrado em Educação - da Universidade Federal do Amapá (Unifap).
\end{abstract}


pose an approach to Scouting as a non-formal/out-of-school education policy in Brazil, emphasizing its legitimacy in the country and the ideals of the Scout movement. And finally, we will present the history of Scouting in the FTA (1945-1947). The research made it possible to understand that although the long time spent to take place in Amapá, the Scout Groups became references in extracurricular education during the Janary Gentil Nunes' Government. They contributed to the governor's interests by disseminating, through their ideals, mechanisms of control, discipline, hygiene, order, love for the country, indispensable for the maintenance of Government in the Territory.

Keywords: History of Scouting. Out-of-school education policy. Federal Territory of Amapá.

\section{Introdução}

A fundação e a implementação do Movimento Escoteiro (ME) ocorreram na Inglaterra, em 1907, sob a responsabilidade do general inglês Robert Baden-Powell, com o intuito de valorizar o sentimento nacionalista/patriótico de amor da juventude pela Nação. Tal experiência inglesa percorreu o Continente e os Estados Unidos e em 1910 foi introduzida no Brasil, primeiramente na cidade do Rio de Janeiro, durante o processo de nacionalização do País.

Tal acontecimento nos instigou a realizar uma pesquisa bibliográfica e documental em relação à história da educação na Amazônia amapaense acerca da implantação e consolidação do ME no ex-Território Federal do Amapá (TFA). Na perspectiva de Rodrigues e França (2010), esse tipo de estudo pode ser realizado a partir de documentos retrospectivos, os quais ainda não receberam um tratamento analítico, ou que podem passar por novas análises dependendo do objetivo da investigação.

Nesse caso, nosso objetivo foi analisar como se deu a realidade que abarca o advento de Grupos Escoteiros no TFA, localizado no extremo Norte da Região Amazônica brasileira, no recorte temporal de 1945-1947. Esse propósito residiu no interesse em investigar no âmago do Escotismo, o teor político educacional de caráter extraescolar do ME que emergiu no espaço amapaense no referido período.

Assim, tivemos como fontes: livros, regulamentos/decreto de lei do ME, arquivos de imagens, relatório de atividades do Governo do TFA (elaborado pelo governador Janary Gentil Nunes) e Jornal Amapá (jornal de notícias do TFA). Tais fontes foram analisadas à luz da História Cultural, vertente analítica que possibilita compreender o 
ME, por meio de práticas e representações, no cerne de suas relações com o contexto no qual se inserem (Chartier, 2002).

Dessa maneira, o referido estudo insere-se no campo do conhecimento da História da Educação, o qual permite uma visão global do processo educativo e possibilita ao educador compreender minunciosamente as suas funções. Sendo que, o conhecimento dos métodos de ensino da herança cultural tem mostrado que não há povo, por mais simples que seja sua organização social, sem um conjunto de meios educativos que garantam sua continuidade no tempo e no espaço. (Saviani, 2007).

Estruturamos o presente texto em três seções. A primeira apresenta um breve histórico do Escotismo, destacando o seu precursor: Baden-Powell (1875-1941), que cria e difunde o Movimento na Inglaterra em 1907 e conquista o mundo. Além disso, enfatizamos o Escotismo no Brasil, para compreensão de como se delineou inicialmente esse processo no contexto nacional. A segunda, aborda o Escotismo como política de educação extraescolar, para tanto, enfatizamos aspectos relativos a sua legitimação, ideais e princípios do ME como complemento da educação formal no Brasil. A terceira, contempla a análise do advento ME no TFA com foco nos anos de 1945-1947, que marcam a implantação dos primeiros Grupos Escoteiros do Amapá.

\section{Breve histórico do Escotismo e origem no Brasil}

Criado na Inglaterra em 1907, início do século XX, por Robert Stephenson Smith, rebatizado como Baden-Powell, o Escotismo é um Movimento de educação extraescolar, em que o espírito de aventura, a observação e a exploração dos elementos da Natureza são alguns dos requisitos que o caracterizam. Esses aspectos foram vividos profundamente por seu precursor, desde a juventude, geralmente em companhia de seus irmãos mais velhos.

Esse Movimento educacional é direcionado para jovens, com a colaboração de adultos, de cunho voluntário e sem vínculo político-partidário. O Escotismo valoriza a participação de pessoas de todas as origens sociais, raças e crenças, de acordo com o propósito, os princípios e o método escoteiro, concebido pelo Major-General Baden Powell. (Suffert, 1995).

Baden-Powell, como se tornou conhecido no mundo inteiro, aos onze anos de 
idade teve seu primeiro contato e acesso aos bancos escolares. Apesar disso, já sabia ler e escrever, além de pintar e desenhar com significativo talento para um menino de sua idade. Estudou piano, e diferentemente do que muitos poderiam imaginar, era avaliado por seus professores como um aluno mediano, e não exemplar ou de alto nível (Boulanger, 2011).

Ressaltamos, ainda, que Baden-Powell não obteve êxito em suas tentativas de ingressar nas universidades de Oxford e Chirst Church, ficando reprovado nos exames das respectivas instituições. Aos dezenove anos de idade, decide fazer o exame para oficial do exército inglês. Foi aprovado e, a partir daquele momento, começou a trilhar uma carreira de sucesso, conquistando várias condecorações e títulos honoríficos _ aos 43 anos foi empossado General, sendo o mais jovem General da história da Inglaterra, reconhecido como Lord Baden-Powell. (Boulanger, 2011).

Ao longo de sua vida Baden-Powell escreveu 35 livros, 21 livretos ou panfletos, mais de 1.500 artigos para o "The Scout" e inúmeros artigos e desenhos para jornais ingleses, o que lhe garantiu o status de respeitado escritor. Em 1908 publicou o livro Scouting for Boys (Escotismo para Rapazes), no qual descreveu as suas experiências militares. (Rabelo, 2012).

Mesmo decorridos mais de cem anos de suas origens, o Escotismo ainda mantém um grande apelo educacional na formação de jovens e crianças, embora a passagem das duas grandes guerras mundiais e da violenta hostilidade sofrida por parte de governos totalitários. O Escotismo já com milhões de adeptos, continuou em expansão, seu valor educativo, demonstrado nestes decênios estribar-se essencialmente no seu realismo sadio, tomando o menino e o rapaz, "tais quais eles são e no seu idealismo sincero, apresentando como metas o domínio de si mesmo e a dedicação aos outros, através de uma vida simples e plena de contato com a natureza." (Ávila, 1967, p. 197).

Por essa razão, o Escotismo foi considerado um Movimento extraescolar, que realiza atividades voluntárias para a formação cidadã de jovens. A priori concebido como um método, prevê a observação para sobrevivência, o zelo pela saúde corporal, noções de cavalheirismo, o patriotismo e técnicas de salvamento, como características fundamentais, as quais o reconhece como um movimento de educação para cidadania.

Não demorou muito para que essa experiência de educação não formal, tida 
como inovadora, chegasse ao Brasil. Tão logo, após 3 anos de sua implantação na Inglaterra, em 1910 ocorre a inserção do Escotismo no Brasil, época em que um grupo de militares da marinha brasileira retornava de uma missão na Inglaterra.

O Tenente Eduardo Henrique Weaver que havia se apresentado em 13 de julho de 1907, à Comissão Naval do Brasil, na Inglaterra, sediada em Newcastle, entusiasmou-se pelo Movimento de Baden-Powell, julgando sua introdução no País útil para nossa pátria. (Blower, 1994). Weaver foi o autor do primeiro artigo sobre Escotismo publicado no Brasil na edição de 1909, da "Revista Ilustração Brasileira". Apesar de ser militar, o Tenente preconizava a sua preocupação em não se fazer do Escotismo uma versão infantilizada do militarismo.

O dia 14 de junho de 1910 foi definido como o dia da implantação e difusão do Escotismo no Brasil, na cidade do Rio de Janeiro, divulgado à imprensa por aqueles que assinaram a ata de sua fundação comunicando a instalação da entidade. O médico Mário Cardim que também foi um dos grandes nomes que contribuíram para a divulgação do Escotismo no Brasil, participou de um curso de Chefe Escoteiro na Europa em 1910, juntamente com Baden-Powell, onde o conheceu pessoalmente (Rabelo, 2012).

O propósito do ME era primeiramente contribuir à formação do jovem, buscando completar aquela exercida pela escola, família, igreja e comunidade, sem o intuito de substituí-las. Com objetivos bem delineados em transformar o menino em um cidadão sabedor de seus direitos e cumpridor de seus deveres, apresentando-lhes e exigindo-Ihes padrões rígidos, rigorosos de obediência e disciplina, o Escotismo ao ser instalado, entusiasmava várias entidades sociais no Brasil como as instituições de ensino, igrejas e clubes esportivos. Nesse pressuposto:

a primeira República configurou-se como momento de importantes transformações na escola paulista, tais como, a expansão do ensino primário, a preocupação com a formação de professores, a atenção cuidadosa para com a construção de espaços apropriados para o ensino, o surgimento de um mercado editorial voltado para temas pedagógicos e o aprimoramento de métodos e práticas pedagógicas como, por exemplo, a introdução do escotismo (Gabriel, 2003, p.14).

As ações do Escotismo ao serem introduzidas nas escolas ou em outros ambientes formais e não formais foram apresentadas como métodos complementares em consonância ao projeto escolar, como sendo, utilitárias em momentos importantes de 
representação do patriotismo em comemorações cívicas. Consistia, até mesmo, em forma de controle concebido pelo Estado, envolvendo determinados sujeitos sociais engajados com a causa educacional. (Gabriel, 2003).

No período entre 1910 e 1924, face aos projetos que ocorriam no Brasil com relação às reformas educacionais na primeira metade do século XX, o Escotismo já se fazia presente em grande parte dos Estados no Brasil. A expansão ocorria de forma expressiva, considerando-se as limitações existentes da época, principalmente no que tange a sua divulgação por meio da imprensa.

A União dos Escoteiros do Brasil (UEB), órgão máximo dos escoteiros no País, criada em 1924 no Rio de Janeiro, alega que a Organização Mundial do Movimento Escoteiro, fundada por Baden-Powell, reúne atualmente mais de 28 milhões de membros, em 216 países e territórios, constituindo-se na maior associação mundial de jovens, com relevante trabalho em busca da paz e da compreensão entre as pessoas, superando diferenças, distâncias e fronteiras (UEB, 2007). O órgão prossegue, registrando que nos dias atuais, o Escotismo passou por ressignificações em virtude de várias mudanças no contexto social, econômico e político no Mundo, após o século XX. O intento do movimento é colaborar para os jovens adquirirem gradualmente seu próprio desenvolvimento, sobretudo o comportamental e o subjetivo pessoal como a formação do caráter, valores e outros. Essa finalidade é contemplada por meio do desenvolvimento das suas potencialidades físicas, intelectuais, afetivas e sociais, auxiliando a serem sujeitos participantes em suas comunidades.

Todavia, o ME passa pela baixa procura de jovens atualmente, pois o Escotismo preza por condutas e comportamentos conservadores considerados internamente sociáveis, como viver em família, dedicar-se aos estudos, bom comportamento, fraternidade, solidariedade e planejamento profissional. Esses valores são subjetivos ao ser humano e, na percepção de muitos, não é viável uma instituição externa determinálos. Desse modo, os novos interessados, ao analisarem tais normas, podem acreditar tratar-se de uma educação doutrinária.

Mais adiante, abordaremos o Escotismo como educação extraescolar no Brasil, destacando a sua legitimação, ideais e princípios do ME como complemento da educação formal, no País. 


\section{Escotismo como Educação Extraescolar}

O começo das atividades escoteiras no Brasil se compara à conjuntura histórica de origem do Movimento, na Inglaterra. Correspondente ao panorama de crise político-social instalada no País durante o século XX, quando ocorreram mudanças nos ideais liberais e no regime político, as quais exigiam também a efetivação de uma sociedade nacionalista e desenvolvimentista para contornar o agravamento dessas questões. Nesse contexto, as ideias congêneres que vinham da Europa foram reinterpretadas e aplicadas ao Brasil e vários intelectuais saíram em defesa da criação de uma identidade coletiva, com a integração de todos para o desenvolvimento da Nação.

Ao término da Segunda Guerra Mundial em 1945, a expressão "extraescolar" se acentuava no contexto da educação não formal. A educação extraescolar obtém sua expansão devido à fragilidade dos sistemas escolares que não conseguiam atender à demanda para com o ensino de seus alunos, o que gerou duras críticas aos sistemas quanto à eficácia do novo processo de educação escolar que se estabelecia (Fávero, 2007). Para o autor, o não formal, tem sido uma categoria utilizada com bastante frequência na área de educação para situar atividades e experiências diversas, distintas daquelas que ocorrem nas escolas, por sua vez classificadas como formais e muitas vezes a elas referidas. Na verdade, há muito tempo classificava-se como extraescolares atividades que ocorriam à margem das escolas, mas que reforçavam a aprendizagem escolar, nas bibliotecas, no cinema, no esporte, na arte.

Com isso, intensificou-se o surgimento de grupos extraescolares que norteavam suas atividades formativas para este fim, no sentido de construir uma sociedade que acatasse às demandas do Estado. Por meio desse pressuposto, o ME era visto como possibilidade de atender e proporcionar uma educação extraescolar direcionada para os interesses nacionalistas daquele período, haja vista que, o pensamento dos nacionalistas brasileiros aproximava-se ao de Baden-Powell. Trata-se da confiança que o desenvolvimento social da nação fomentaria "cidadãos conscientes" das reais condições de seu país, preparando-os para superar as adversidades e os desafios causados pelas transformações econômicas e sociais.

Nesta perspectiva, pelo Decreto-Lei n. 8.828/1946 o Escotismo passa a ser legalizado no Brasil como uma das diversas formas de educação extraescolar. Em seus arti- 
gos se torna perceptível sua legalização conforme o exposto:

Art. 10 - Fica reconhecida a União dos Escoteiros do Brasil no seu caráter de instituição destinada à educação extraescolar, como órgão máximo de escotismo brasileiro.

Art. 2ㅇ - A União dos Escoteiros do Brasil manterá sua organização própria com direito exclusivo ao porte e uso dos uniformes, emblemas, distintivos, insígnias e terminologia adotados nos seus regimentos e necessários à metodologia escoteira.

Art. 3ㅇ - A União dos Escoteiros do Brasil realizará, mediante acordo, suas finalidades em cooperação com o Ministério da Educação e Saúde.

Art. 4ㅇ - A União dos Escoteiros do Brasil será anualmente concedida no orçamento geral da República, a subvenção necessária para a satisfação dos seus fins. (BRASIL, Decreto 8.828/1946, p. 332).

O ME semeia em sua essência o espírito voluntário, buscando trabalhar nos jovens, princípios norteadores, para que sejam "bons" cidadãos. A ordem ética, moral, espiritual e intelectual são princípios vivenciados no campo, por meio de acampamentos, excursões, jogos, competições e teatro, externas aos ambientes fechados das escolas. Por isso, as atividades são realizadas ao ar livre, na Natureza, com a finalidade de serem executadas em diferentes ambientes da vida.

O enfoque do ME, conforme Suffert (1995), define-se em contribuir para que os jovens assumam o seu próprio desenvolvimento, especialmente do caráter, os ajudando a realizar suas plenas potencialidades físicas, intelectuais, sociais, afetivas e espirituais, como cidadãos responsáveis, participantes e úteis em suas comunidades, conforme definido no projeto da União dos Escoteiros no Brasil. Diante dessa forma de ensinar, a Pedagogia possibilitava ao ME bases para a estruturação e divisão por faixa etária de seus integrantes, a UEB (2007) destaca os diferentes ramos do Escotismo: 1) Lobinhos (7-10 anos); 2) Escoteiros (11-14 anos); 3) Sênior (15-17 anos); 4) Pioneiros (18-21 anos).

É importante perceber a divisão e a organização dos ramos dentro de cada grupo, a forma como são estabelecidas e escolhidas atividades, o foco na faixa etária dos indivíduos, assim como a intencionalidade pedagógica e educativa que deve haver em cada tarefa realizada. Cabe inferirmos que não é atividade por atividade ou brincar por brincar _ é algo maior que está relacionado ao desenvolvimento educacional dos sujeitos envolvidos. 
O Escotismo é a pedagogia organizada no início do século XX, baseada em ensinar disciplina aos jovens, fixar valores, desenvolver habilidades e difundir conhecimento, de acordo com os paradigmas de práticas da Pedagogia Moderna que se estabeleceram fortemente naquele período (Nascimento, 2008). É necessário ressaltar que, mesmo o Escotismo sendo um Movimento tido como projeto de educação extraescolar de caráter complementar à educação escolar, era inevitável que não influenciasse no interior das escolas.

O desenvolvimento do propósito, princípio e métodos do Escotismo, conta com contingentes de adultos voluntários que passam por uma formação para atuarem como escotistas e dirigentes. Portanto, os Grupos Escoteiros, por meio de seus diretores e representantes legais, passam por cursos de capacitação para comandarem às tropas. (Barreira, 2006).

Os princípios e ideias de condutas são definidos na promessa escoteira, que caracteriza o espírito escoteiro e vem representar um compromisso também de vivência externa ao Escotismo e para toda a vida. Ajusta-se aos progressivos graus de maturidade do indivíduo e sempre acompanhando os valores presentes nos ideais de BadenPowell (1993) - missão, visão, princípios, desenvolvimento físico, desenvolvimento moral e desenvolvimento intelectual - a Organização Mundial do Movimento Escoteiro define como princípios do Escotismo: dever para com Deus (crença e vivência de uma fé, independentemente de qual seja); dever para com os outros (participação na sociedade, boa ação e serviço ao próximo); dever para consigo próprio (crescimento saudável e autodesenvolvimento).

No que se refere aos princípios do Escotismo, o primeiro reflete a religião, no qual o desejo é que o jovem busque atitudes espirituais. O segundo, trata do dever para com o próximo, quer seja amigo ou outra pessoa ainda não vista à sua frente, já o terceiro princípio é em relação ao dever para consigo mesmo e vem para assegurar a ponderação de responsabilidade que o jovem deverá buscar assumir ao longo de sua vida. A lei escoteira se expressa da seguinte forma:

O escoteiro tem uma só palavra; sua honra vale mais que sua própria vida;

O escoteiro é leal;

O escoteiro deve estar sempre alerta para ajudar o próximo; 
O escoteiro é amigo de todos e irmão dos demais escoteiros;

O escoteiro está sempre alerta para ajudar o próximo e pratica diariamente uma boa ação;

O escoteiro é cortês;

O escoteiro é bom para animais e plantas;

O escoteiro é obediente e disciplinado;

O escoteiro é alegre e sorri nas dificuldades;

O escoteiro é ecumênico e respeita o bem alheio;

O escoteiro é limpo de corpo e alma. (Baden-Powell, 1993).

Essa lei é um código para a vida de cada escoteiro, individualmente, e para os membros de cada grupo, coletivamente, baseado nos princípios do Escotismo. Em virtude da vivência deste código aplicado no cotidiano, a lei proporciona uma maneira concreta e prática para cada jovem compreender os valores que o ME propõe como base para a vida.

Sobre a promessa é um compromisso pessoal de fazer o seu melhor possível. Para viver de acordo com esse código, cada jovem assume perante seu grupo de pares, quando ele ou ela decide integrar-se ao ME. Ao assumir a promessa escoteira, o jovem toma uma decisão consciente e voluntária de aceitar a lei escoteira e assumir a responsabilidade dessa escolha mediante esforço próprio para "fazer o melhor possível". (Nascimento, 2008).

O fato de assumir a promessa diante de seus pares, não só torna público o comprometimento pessoal, como também simboliza o compromisso social com os demais. Assumi-la representa o primeiro passo no processo educacional. A lei e a promessa são consideradas como um único elemento, pelo fato de estarem intimamente ligadas, como um sistema de progressão com a intenção de estimular que os jovens desenvolvam suas capacidades e seus interesses, incentivando a superação de desafios, a exploração, o desejo por aventura, a descoberta, a iniciativa, a invenção, a criação etc. O método escoteiro baseia-se em: aceitação da lei e promessa escoteira; aprender fazendo; vida em equipe; atividades progressivas, atraentes, variadas; e desenvolvimento pessoal com orientação individual.

Segundo o fundador do ME, Baden-Powell, a grande mestra dos jovens deve ser a Natureza. Os bosques a explorar, as montanhas a conquistar, os rios a percorrer constituem a grande escola da vida, ignorada por muitos jovens. A filosofia escoteira acredita que a partir do momento em que a criança e o jovem entram em contato com 
a Natureza, aprendem e adquirem o equilíbrio necessário para conviver em sociedade, e reconhecer-Ihe a importância para a sobrevivência das pessoas, inclusive a sua própria.

Apresentamos a seguir o advento do Escotismo no TFA (1945-1947). Para tanto, analisaram-se os resultados e discussões acerca dessa investigação, que irão evidenciar a implantação dos primeiros Grupos Escoteiros amapaenses.

\section{0 advento do Escotismo no Território Federal do Amapá no século XX}

No início do século XX, primeiras décadas da Proclamação da República brasileira, as terras que hoje constituem o Amapá faziam parte do Estado do Pará e estavam sob o domínio do governo paraense. Nesse panorama, essa região padecia de assistência nos diversos setores de vida da população, em função de negligência administrativa por parte dos dirigentes locais. No dia 13 de setembro de 1943, pelo DecretoLei n. 5.812, ato presidencial de Getúlio Vargas, o Amapá foi elevado à condição de Território Federal. Ainda ao final do referido ano, o Presidente Vargas nomeou, no dia 27 de dezembro, o Capitão do Exército brasileiro Janary Gentil Nunes, como o primeiro governador do então Território.

A situação crítica em que se encontrava o Amapá, conforme o diagnóstico inicial descrito no relatório de atividades do primeiro governo do TFA, evidenciava que os amapaenses estavam em completo abandono pelos governos liberais anteriores. Diante disso, proporcionar o "progresso" para essa região fizera o governador Janary Nunes eleger a educação como instrumento privilegiado na busca desse ideal (Nunes, 1946).

Com sua chegada, nos primeiros meses de 1944, Janary Nunes realiza a instalação das primeiras instituições de ensino do TFA, com aluguel de várias casas e outras cedidas para o funcionamento provisório de escolas isoladas e mistas. Além disso, naquele ano, começara a edificação de educandários da categoria de Grupo Escolar (GE), que no caso deste primeiro, denominou-se "GE de Macapá", inaugurado em 1946, no centro urbano da cidade de Macapá, que teve seu nome modificado, em forma encomiástica, para "GE Barão do Rio Branco".

Os administradores republicanos, em geral, almejaram por meio de inúmeras medidas colocar em prática o projeto de modernização da sociedade e de construção 
da nova nação brasileira. Investiram em símbolos nacionalistas como bandeiras, hinos, heróis (nacionais/locais) e, notadamente, atuaram na reelaboração do processo educativo escolar. O cenário daquela época auxilia a nossa compreensão sobre a adesão ao Escotismo por parte de vários agentes republicanos desde 1910, quando o Movimento desembarca no Brasil. A República traz várias funções para a educação escolar como instruir as crianças, formá-las cidadãs "civilizadas" e amantes da Pátria de forma que o Escotismo foi considerado por intelectuais e políticos brasileiros republicanos, uma das práticas extraescolares fundamentais para o desenvolvimento do civismo e do nacionalismo (Sousa, 2000; Zuquim e Cytrynowicz, 2002).

A educação em destaque tornava-se necessária por instruir a população e inculcar valores republicanos de sociedade como disciplina, higiene, patriotismo, ordem, progresso, e ambição pela prosperidade individual e coletiva. Tais componentes eram quistos pelo governador Janary Nunes, para que fossem difundidos no TFA por meio da educação, sobretudo por instituições escolares e extraescolares, como os Grupos Escoteiros. Nesse sentido, Nunes (1946, p. 34) impunha uma educação que pudesse:

Intervir em todos os setores de atividades [...] ensinando a alimentação, vestuário, o exercício, a alegria, o conforto à criança; incutindo em cada indivíduo a noção de que pertence à coletividade brasileira; difundindo as diretrizes da geopolítica nacional de forma simples e acessível, para que se tornem cogitação popular; plasmando a ânsia de melhorar seu corpo, sua família, sua Pátria.

Logo, uma educação que interviesse em todos os segmentos sociais, propagando o zelo por ordem, disciplina e amor à Pátria proporcionava o apoio direto e oficial do governador Janary Nunes. Isso influenciava seu posicionamento favorável, destinado ao Escotismo como um movimento educacional não formal, de atividade extraescolar, convenientemente adaptada ao meio brasileiro (Nunes, 1946, p. 36).

A importância da implantação do Escotismo no Amapá, corresponde ao fato de que tal Movimento enveredava por uma formação "integral” dos cidadãos, o que se confirmava em função de sua crescente difunsão no Brasil. Assim sendo, o Escotismo foi diretamente estimulado pelo então Departamento de Educação e Cultura do TFA, que além de prever instalações e materiais, deveria promover à vinda de Chefes e as 
suas formações em cursos locais, pois o ME e bandeirante tinham que "estender-se dia a dia a todos os núcleos de população, pela disseminação de patrulhas, grupos e associações" que congregassem sob suas bandeiras e símbolos a maioria da juventude amapaense (Nunes, 1946, p. 36).

O sentimento nacionalista em torno da construção do TFA que se pretendia "civilizar" e "desenvolver" aos moldes europeus e republicanos recebeu com bons olhos o ME e então as ideias originais de Baden-Powell também encontraram ressonância nas terras amapaenses. Assim, os alunos matriculados nos Grupos Escolares eram considerados aspirantes ao Escotismo. Nessa perspectiva, no dia 7 de setembro de 1945, para comemorar os festejos da "Semana da Pátria", Janary Nunes convidou o presidente da organização escotista de Belém/PA, o capitão Castelo Branco, representando a Federação Paraense de Escoteiros. Na ocasião, a viagem ocorreu na lancha a motor "Amapá", com 22 escoteiros para visitar a cidade de Macapá, capital do TFA (AMAPÁ, [jornal] Amapá, 1944).

Dentre as atividades a serem apresentadas ao público por essa delegação de escoteiros estavam: teatro, turmas de luta livre, voleibol e futebol (Simonel et al., 2000). Seriam os primeiros indícios influenciadores para a criação de um Grupo Escoteiro, no TFA. Dessa forma, no dia 12 de setembro de 1945, foi fundada a célula elementar na capital macapaense, o primeiro Grupo Escoteiro, posteriormente denominado "Grupo Escoteiro Veiga Cabral", a seguir ilustrado na foto 1:

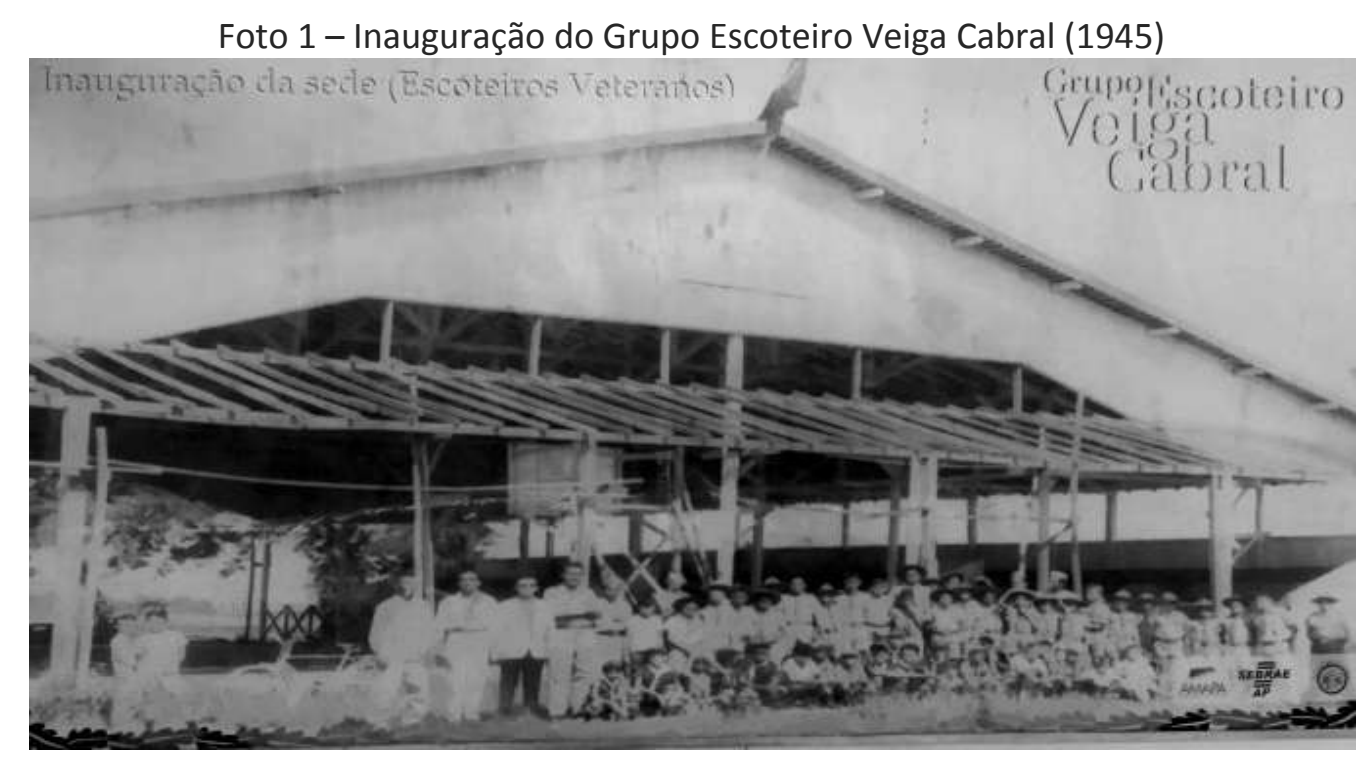

Fonte: Acervo do Grupo Escoteiro Veiga Cabral. 
O primeiro nome do referido grupo de escoteiros foi Associação de Escoteiros do Amapá, e tinha como sede a Praça Veiga Cabral, sendo renomeado em homenagem ao considerado herói Francisco Xavier da Veiga Cabral (General Honorário do Exército Brasileiro, expoente de resistência brasileira contra a tentativa de dominação Francesa em relação às terras do Amapá, ocorrida em 15 de maio de 1895). Os escoteiros pioneiros desse grupo, foram: José Ribamar de Moura, que era Juiz de Direito da Comarca de Macapá (presidente); Alamiro de Souza (secretário); Amiraldo Nobre (tesoureiro); cabendo a tarefa de organização do Movimento ao chefe Glicério de Souza Marques e aos escoteiros Clodoaldo Carvalho do Nascimento e José Raimundo Barata. Os chefes escoteiros, como tinham que se manter no TFA, acabavam ganhando cargos na administração territorial (Simonel et al., 2000).

O Escotismo, conforme o Jornal Amapá (1946, p. 2-3) procurava “influenciar o espírito dos jovens". Para isso, os pais deveriam também se interessar pelo desenvolvimento daquela "moderna" escola de educação cívica da mocidade, à qual o governo territorial prestava o mais decidido apoio, com o intuito de levantar o nível moral e cívico dos rapazes amapenses.

No dia 20 de julho de 1946, membros do Governo e moradores da cidade participaram da cerimônia solene dos primeiros Escoteiros do Território. Na ocasião, jovens prometeram diante da Bandeira do Brasil cumprir o seu dever para com Deus e a pátria, ajudar ao próximo em toda e qualquer situação e obedecer fielmente à lei dos escoteiros. Diante desse cenário, o ME foi ganhando força com o surgimento de novas associações, difundindo-se em Macapá e demais municípios, procurando difundir a escola ativa de Baden-Powell em todo o Território. Nesse pressuposto, Lobato (2009) menciona que foram criadas em 1946 as Associações: Lobo d' Alma, (Mazagão); Barão do Rio Branco (Amapá); Joaquin Caetano (Oiapoque), dentre outros. Os escoteiros participavam dos desfiles nas festas cívicas e também, organizavam atividades como torneios, peças teatrais e excursões, sempre contando com o patrocínio governamental. A ilustração a seguir é representativa dessa situação: 
Foto 2 - Escoteiros do Grupo Veiga Cabral em desfile cívico [19--]

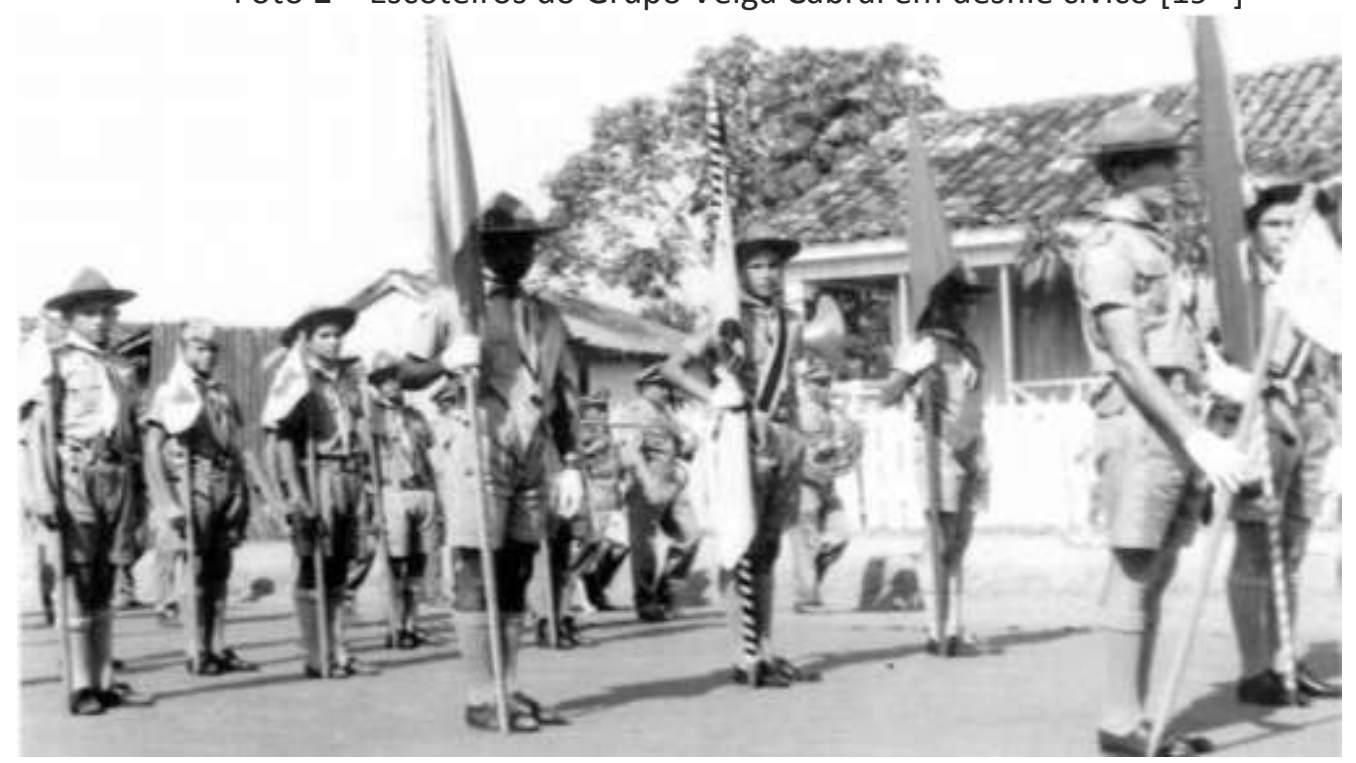

Fonte: Acervo do Museu Histórico do Amapá.

No dia 13 de julho de 1947, deu-se a fundação do Grupo Escoteiro do Mar Marcílio Dias, por iniciativa do professor de Educação Física e chefe escoteiro Dário Cordeiro Jassé, que chegara à cidade de Macapá três meses antes. Exercia a função de professor primário, destacando-se na função de inspetor de ensino, a convite do Governador Janary Nunes (AMAPÁ, Amapá, 1947). Consequentemente, a trajetória extraescolar que o Escotismo traçou no TFA, imposta pelo Governo, sob o argumento da necessidade de constituir e desenvolver a identidade nacional republicana, provocou de maneira induzida o entusiasmo dos amapaenses pelo ME.

De acordo com o então Presidente da Federação Amapaense de Escoteiros, Marcílio Felgueiras Vianna, a finalidade dessas instituições era incentivar a preparação moral, cívica e cristã da juventude amapaense. De tal modo que, o Escotismo tomara impulso na região, "integrando" cada indivíduo por princípios da moral cristã, moldando o caráter, a saúde física, o "desenvolvimento da raça", a prática dos desportos, "além de prescrever a necessidade do asseio oral, habituando os moços a cultuarem os símbolos sagrados da nacionalidade" (AMAPÁ, Amapá, 1947, p. 2).

Destarte, percebemos por meio das fontes, uma época de controle sobre os indivíduos que se realizava simultaneamente nos espaços religiosos, escolares e extraescolares, expressando-se como Movimento evidendemente educativo nas entrelinhas de discursos preconceituosos. Isso em detrimento da tradição comum da 
população, que terminava sendo combatida, ao ser considerada contaminada por "doutrinas exóticas", que tentariam desviar os jovens do caminho "mais correto" de vida.

Entre as atividades escoteiras, a foto 3 é representativa de que ocorriam acampamentos e solenidades integrantes de cursos preliminares para chefes de lobinhos, que reuniam representantes de diferentes Grupos Escoteiros do TFA, realizado pela UEB.

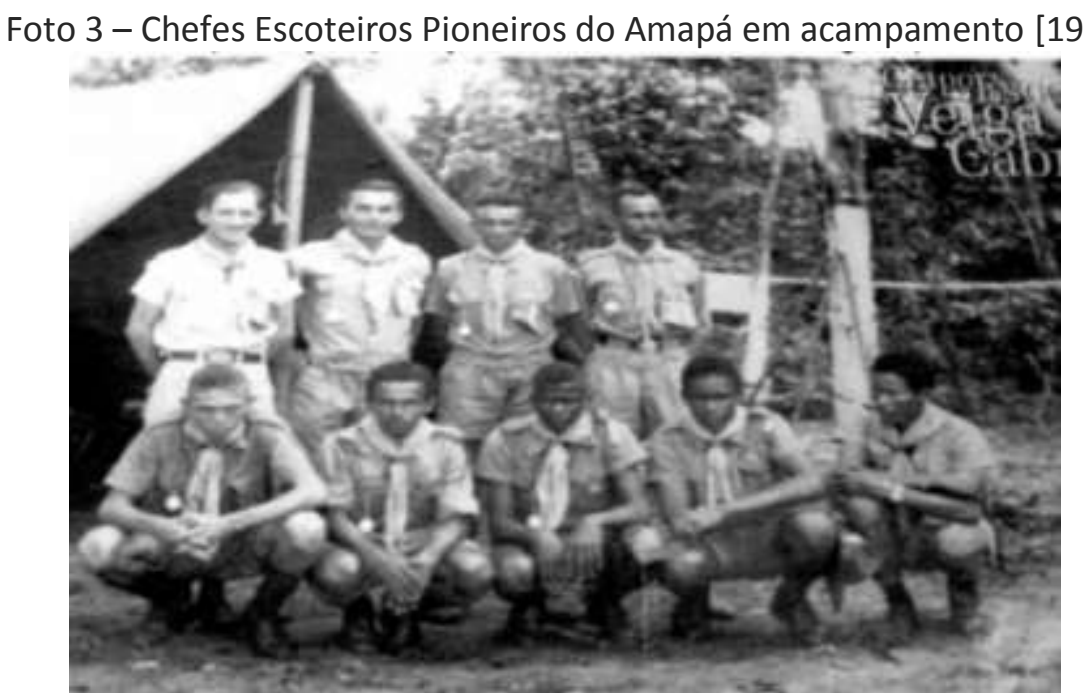

Fonte: Acervo do Grupo Escoteiro Veiga Cabral.

O Escotismo era visto como um elo da política educacional amapaense, que ligava meninos e meninas aos valores considerados necessários para o progresso dentro da ordem social hierarquisada e disciplinada. Tido como um estilo de vida sadio que poderia influenciar a vida de muitos jovens, pois diante de uma sociedade com seus valores éticos e morais "corrompidos", representava um caminho para que os adolescentes se tornassem adultos responsáveis e conscientes (Lobato, 2009).

No TFA, a tentativa de militarização da infância, por meio do Escotismo, foi o caminho adotado por aqueles que almejavam, no Brasil, transformar o movimento fundado por Baden Powell em política de Estado, mesmo não sendo a militarização o objetivo de seu percursor mundial. Á luz de Lobato (2009), Janary Nunes e seus assessores também abusavam de representações concernentes às práticas militares para descrever o perfil das ações educacionais que o Governo territorial estava empreendendo. 
Não obstante, a militarização da infância revelava como fora pensado no Amapá a educação escoteira articulada ao ensino ofertado nos Grupos Escolares. Uma educação que conciliava a educação moral e cívica às políticas relativas ao civismo, patriotismo e nacionalização, na tentativa de transformar as escolas primárias em máquinas de "civilização" de corpos e mentes.

Os principais líderes e dirigentes de educação viam o Escotismo com um molde educativo que poderia complementar o trabalho das escolas, proporcionando ao Movimento a importância, valorização, legitimação e reconhecimento oficiais. Logo, os Grupos Escoteiros eram indispensáveis para a manutenção do Governo, que exercia controle sobre os amapaenses. O Escotismo, vinculado ao Movimento nacionalista brasileiro, foi introduzido como uma prática cívico-patriótica no TFA. Nesse decurso, formar o cidadão "moralmente educado" constituiu o discurso para a implantação do Escotismo como atividade extraescolar no Amapá.

Diante do exposto, a prática escoteira no TFA encarnava uma função educativa completa, unindo a formação do corpo e da alma, correspondendo ao projeto cívico de constituição da nacionalidade brasileira. Dessa forma, percebemos o valor educacional atribuído ao Escotismo, por Janary Nunes, para além de instrumento de educação moral e cívica, pois impunha de forma sutil um padrão de sociedade, na qual os sujeitos do Amapá participariam de sua manutenção sem questionar os ditames do Governo Janarista.

\section{Considerações finais}

Nesse texto, objetivamos analisar o advento do Movimento Escoteiro no Território Federal do Amapá, de 1945 a 1947. Para tanto, realizamos uma breve discussão dos motivos que levaram a tal estudo, e o referencial teórico-metodológico que subsidiou os resultados apresentados até então.

Com base em análises sobre a implantação e consolidação dos Grupos Escoteiros no Brasil, podemos mencionar que tal Movimento foi de grande importância para o projeto de Governo do TFA no que se refere à difusão e inserção de uma política de educação não formal, que visava à disseminação de atividades extraescolares para crianças, jovens e adultos. 
No TFA, como pudemos perceber, o ME levou bastante tempo para se efetivar, ou seja, 35 anos após a criação do primeiro Grupo Escoteiro criado no Brasil (no Rio de Janeiro em 1910) é que se instala o pioneiro Grupo Escoteiro no Amapá, o “Veiga Cabral" (na cidade de Macapá). Logo em seguida é que se intensifica a criação de novos grupos não só na capital macapaense, como também, no interior do então Território.

Ressaltamos que só foi possível aderir ao referido Movimento quando essa parte da Região Amazônica alcançou a condição de Território Federal, fato indispensável para o surgimento dessas instituições no Amapá. O Escotismo, de imediato encaixarase junto à política educacional do primeiro governador do TFA, que acreditava na "formação integral" do cidadão conforme convinha. Nesse sentido, Janary Nunes apoiou o Movimento e sua difusão como parte integrante de suas ações governamentais, visando fixar na população o modelo "ideal" de cidadão e de vida.

Consideramos que o Escotismo corroborava com os intentos do Governo do Amapá em estabelecer ideais educativos de disciplina, higiene, patriotismo, ordem, progresso, dentre outros aspectos de interesse do governo local e da nação brasileira. Tais ideais visavam transformar alunos em cidadãos, em face de uma formação integral, com base em preceitos pautados no progresso dentro da ordem social hierarquizada, disciplinadora e moralizadora.

Por fim, evidenciamos que ainda há muito a ser pesquisado sobre a história do Movimento Escoteiro no Amapá, aspectos que ainda se encontram silenciados na História da Educação, como: quais os critérios para a participação/ingresso de Chefes e novos adeptos ao Escotismo na época? Como funcionavam as atividades e de que maneira eram planejadas para serem aplicadas/executadas? Qual era o perfil dos seus integrantes? Que instrumentos materiais/logísticos eram utilizados? dentre outros aspectos a serem explorados.

\section{llustrações}

Foto n. 1: ACERVO DO GRUPO ESCOTEIRO VEIGA CABRAL. Inauguração do Grupo Escoteiro Veiga Cabral. Macapá,: [S. ed.], 1945.

Foto n. 2: ACERVO DO MUSEU HISTÓRICO DO AMAPÁ. Pelotão de escoteiros do grupo Veiga Cabral em desfile cívico. Macapá: [S. ed.], [19--].

Foto n. 3: ACERVO DO GRUPO ESCOTEIRO VEIGA CABRAL. Chefes Escoteiros Pioneiros do Amapá em acampamento. Macapá: [S. ed.], [19--]. 


\section{Referências}

AMAPÁ. [jornal] Amapá. Macapá, 7 set. 1944.

. Amapá. Macapá, 13 jul. 1946, p. 3.

Amapá. Macapá, 1947, p. 2.

ÁVILA, Fernando Bastos. Pequena enciclopédia de moral e civismo. Rio de Janeiro: DNE/MEC, 1967.

BADEN-POWELL, Robert Stephson Smith. Escotismo para rapazes. 4a edição. São Paulo: Editora Escoteira. 1993.

BARREIRA, Karla Vignoli Vegas. Prática em extinção ou em processo de renovação? Um estudo sobre a supervisão educacional. Dissertação (Mestrado em Educação) - Faculdade de Educação, Universidade Federal de Minas Gerais, Belo Horizonte, 2006.

BLOWER, Bernard David Almirante. História do Escotismo brasileiro: os primórdios do Escotismo no Brasil. Vol. I. Tomo I - 1910-1924. Rio de Janeiro: CCME, 1994.

BOULANGER, Antônio. O Chapelão: histórias da vida de Baden-Powell. Rio de Janeiro: Letra Capital, 2011.

BRASIL. Decreto n. 8.828, de 24 de janeiro de 1946. Dispõe sobre o reconhecimento da União dos Escoteiros do Brasil como instituição destinada a educação extraescolar. Rio de Janeiro.

CHARTIER, Roger. A história cultural: entre práticas e representações. 2a ed. Lisboa: DIFEL, 2002.

FÁVERO, Osmar. Educação não-formal: contextos, percursos e sujeitos. Educação e Sociedade. Campinas, v. 28, n. 99, maio/ago. 2007.

GABRIEL, Yara Cristina. Prescrições cívico-morais e a formação do cidadão: um estudo sobre a introdução do escotismo nas escolas públicas de São Paulo (1917-1922). Dissertação (Mestrado em Educação). PUC-SP, 2003.

LOBATO, Sidney da Silva. Educação na fronteira da modernização: a política educacional no Amapá (1944-1956). Belém: Paka-Tatu, 2009.

NASCIMENTO, Jorge Carvalho do. A escola de Baden-Powell: cultura escoteira, associação voluntária e escotismo de Estado no Brasil. Rio de Janeiro: Imago, 2008.

NUNES, Janary. Relatório das atividades do Governo do Território Federal do Amapá em 1944. Rio de Janeiro: Imprensa Nacional, 1946.

RABELO, Ricardo Rocha. "Uma vez Escoteiro, sempre Escoteiro": marcas da Educação Escoteira em Sergipe (1958-2009). Dissertação (Mestrado em Educação) - Universidade Tiradentes, Aracaju, 2012.

RODRIGUES, Denise de Souza Simões; FRANÇA, Maria do Perpétuo Socorro Gomes de Souza Avelino de. Uso do documento em pesquisa sócio-histórica. In: MARCONDES, Maria Inês et al. (Org.). Metodologias e técnicas de pesquisa em educação. Belém: EDUEPA, 2010, p. 55-74.

SAVIANI, Dermeval. Instituições escolares no Brasil: conceito e reconstrução histórica. In: NASCIMENTO, M. I. M et al. (Org.). Instituições escolares no Brasil: conceito e reconstrução histórica. Campinas: Autores Associados, 2007, p. 3-27.

SOUZA, Rosa Fátima de. A militarização da infância: Expressões do nacionalismo na cultura brasileira. Cadernos CEDES, v. 20, n. 52, nov, 2000.

SIMONEL, Jean Etienne et al. 55 anos de escotismo no Amapá. Macapá: Impressa Oficial do Estado do Amapá, 2000.

SUFFERT, Rubem. Compreendendo os fundamentos do escotismo. Brasília: Editora Es- 
coteira da UEB, 1995.

UNIÃO DOS ESCOTEIROS DO BRASIL (UEB). Comissão Nacional de Programa de Jovens: as características essenciais do escotismo. 3 ed. Curitiba, PR: 2007.

ZUQUIM, Judith; CYTRYNOWICZ, Roney. Notas para uma história do escotismo no Brasil: a "psicologia escoteira" e a teoria do caráter como pedagogia de civismo. (19141937). Educação em Revista. Belo Horizonte, n. 35, p. 43-58, 2002.

Artigo recebido em agosto de 2018 e aceito em novembro de 2018. 